\title{
Modelling the mechanical behaviour of typical wall-to-floor connection systems for cross-laminated timber structures
}

\author{
Matteo Izzi ${ }^{\mathrm{a}, \mathrm{b}, *}$, Andrea Polastri ${ }^{\mathrm{a}}$, Massimo Fragiacomo ${ }^{\text {, a }}$ \\ ${ }^{a}$ National Research Council of Italy - Trees and Timber Institute (CNR IVALSA), Via Biasi 75, 38010 San Michele all'Adige, Italy \\ ${ }^{\mathrm{b}}$ Department of Engineering and Architecture, University of Trieste, Piazzale Europa 1, 34127 Trieste, Italy \\ ${ }^{\mathrm{c}}$ Department of Civil, Construction-Architectural and Environmental Engineering, University of L'Aquila, Via Gronchi 18, 67100 L'Aquila, Italy
}

\section{A R T I C L E I N F O}

\section{Keywords:}

Cross-laminated timber

Annular-ringed shank nail

Steel-to-timber joint

Metal connector

Wall-to-floor connection

Non-linear modelling

Hysteretic behaviour

\begin{abstract}
A B S T R A C T
This paper proposes a numerical model capable of predicting the mechanical behaviour and the failure mechanism of typical wall-to-floor connections for Cross-Laminated Timber structures. Such systems are assembled with angle brackets and hold-downs, anchored to the wall and floor panels with profiled nails and bolts. The metal connector and the elements to which it is fastened are modelled using 3D solid bodies, while the steel-totimber joints are simulated as non-linear hysteretic springs. Shear and tension tests are reproduced on two connection systems and results are compared to the test data obtained from similar configurations. Simulations lead to accurate predictions of the mechanical behaviour (i.e. elastic stiffness, maximum load-carrying capacity, and shape of the hysteresis cycles) and energy dissipation. Finally, the performance when lateral and axial loads are applied simultaneously is investigated. Analyses are carried out by varying the inclination of the load, with respect to the axis of the connector, between $0^{\circ}$ and $90^{\circ}$. Results exhibit a quadratic interaction relationship between shear and tension loads, and prove that their coupled effect influences the stiffness and the maximum load-carrying capacity.
\end{abstract}

\section{Introduction}

As a structural product, Cross-Laminated Timber (CLT) exhibits a high in-plane stiffness and a linear-elastic behaviour with tendency to fail with brittle mechanisms (except for compressive stresses). Therefore, mechanical connections between CLT walls and floor panels represent the ductile zones of CLT structures, supplying the strength, stiffness, and energy dissipation under seismic conditions [1].

The mechanical behaviour of wall-to-floor connection systems for CLT structures has been the focus of several research projects. Shear and tension tests have been carried out on different types of angle brackets and hold-downs, varying the geometry of the connectors and the number of nails [2-6]. Recently, tests have been performed under the simultaneous application of lateral and axial loads, highlighting that the coupled shear-tension action affects the stiffness, the loadcarrying capacity and the energy dissipation $[7,8]$.

The increasing use of CLT for the construction of mid- and high-rise structures (the so-called 'tall buildings') requires connections with excellent mechanical properties and large ductility ratios. However, the outcomes of past test programmes highlighted some inappropriate failure mechanisms that might limit the application of the metal connectors currently available on the market. In particular (Fig. 1): in connections with angle brackets, $(a)$ withdrawal of the nails connected to the floor panel or (b) pull-through of the anchoring bolts; $(c)$ in connections with hold-downs, tensile failure in the net cross-section of the metal flange. Such failure mechanisms might be associated to an incorrect design of the steel-to-timber joints and could be prevented by over-strengthening those parts of the connections [9].

Improving the mechanical performance of the connection systems currently available on the market and developing new solutions is an expensive and time-consuming procedure, requiring consideration of several factors (e.g. thickness of the metal member, nails number and position, anchoring) and loading cases. Therefore, to limit the need of experimental tests to a minimum, great effort should be devoted to develop advanced numerical models capable of extending the data available to other situations of interest.

This paper proposes a numerical model capable of predicting the mechanical behaviour and the failure mechanism of typical wall-tofloor connections with angle brackets and hold-downs. The metal connector and the panels where it is anchored are modelled as 3D solid bodies, while the nailed steel-to-timber joints are simulated as nonlinear hysteretic springs with a UEL (User Element Subroutine) taken

\footnotetext{
* Corresponding author at: National Research Council of Italy - Trees and Timber Institute (CNR IVALSA), Via Biasi 75, 38010 San Michele all'Adige, Italy.

E-mail address: izzi@ivalsa.cnr.it (M. Izzi).
} 

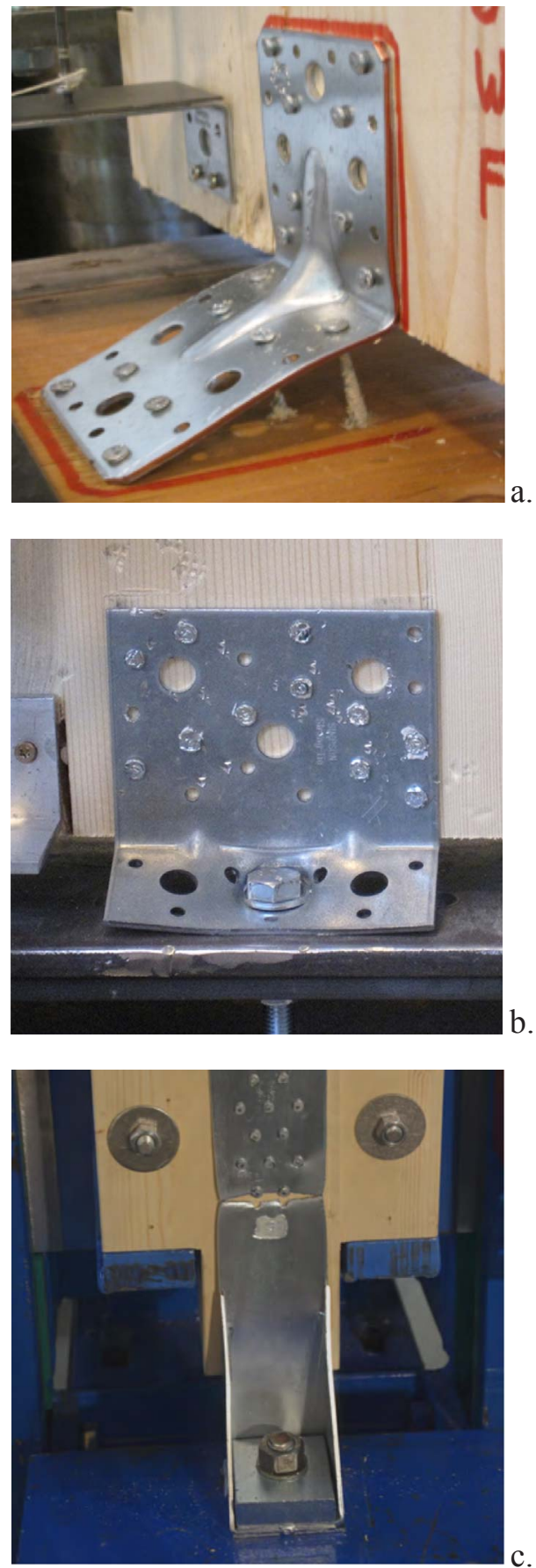

Fig. 1. Inappropriate failure mechanisms at the connection level: (a) withdrawal of the nails connected to the floor panel; (b) pull-through of the anchoring bolt, and (c) tensile failure in the net cross-section of the metal flange (courtesy of CNR IVALSA and University of Trento, Italy).

from Rinaldin et al. [10]. Shear and tension tests are reproduced on two connection systems and results are compared to the experimental data obtained from similar configurations. Finally, the mechanical

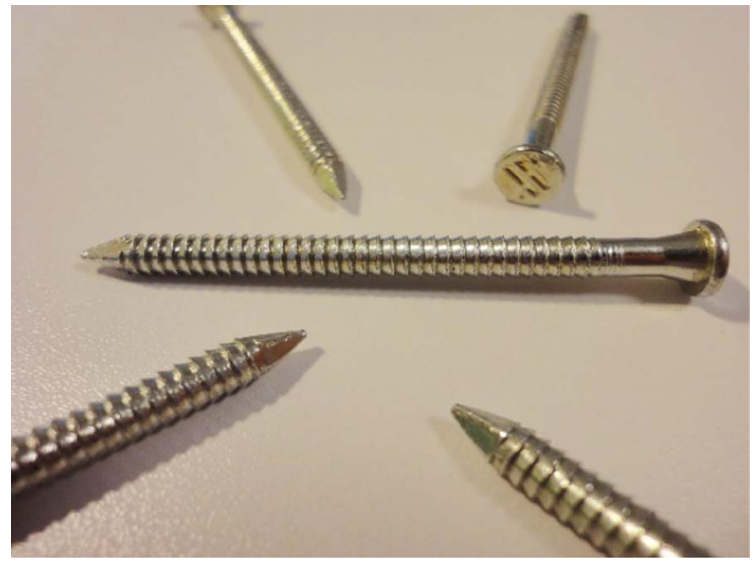

Fig. 2. Annular-ringed shank nails (reproduced from Izzi et al. [9]).

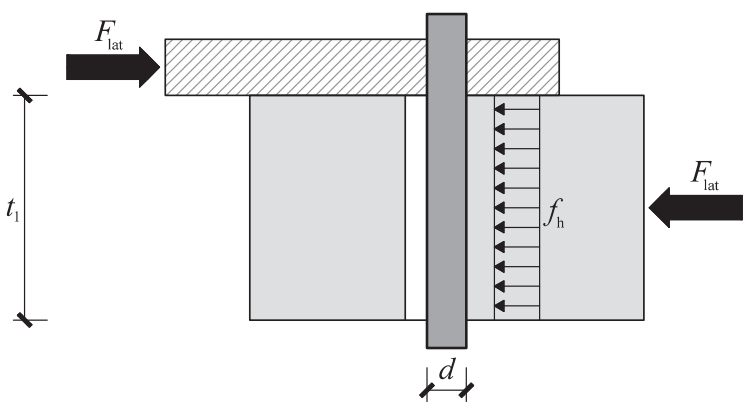

a.
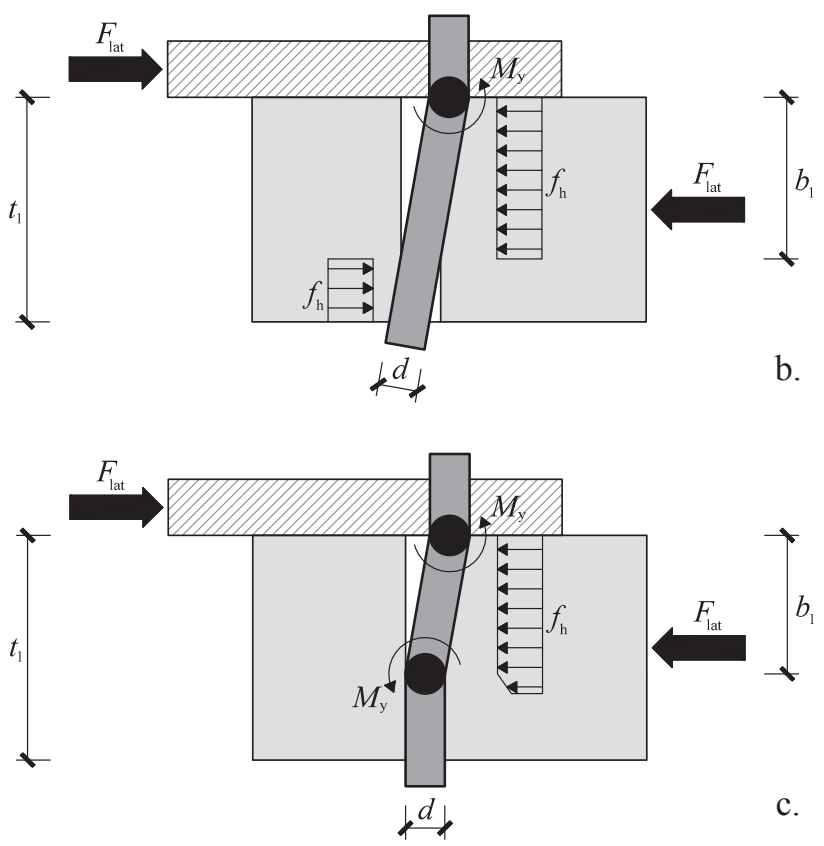

Fig. 3. Failure mechanisms of a nailed steel-to-timber joint with a thick metal plate (adapted from Flatscher [40] and Hilson [13]).

Table 1

Material parameters for Norway spruce (Picea abies), taken from Fortino et al. [12].

\begin{tabular}{|c|c|c|c|c|c|c|c|c|}
\hline$E_{\mathrm{R}}[\mathrm{MPa}]$ & $E_{\mathrm{T}}[\mathrm{MPa}]$ & $E_{\mathrm{L}}[\mathrm{MPa}]$ & $\nu_{\mathrm{RT}}[-]$ & $\nu_{\mathrm{RL}}[-]$ & $\nu_{\mathrm{TL}}[-]$ & $G_{\mathrm{RT}}[\mathrm{MPa}]$ & $G_{\mathrm{RL}}[\mathrm{MPa}]$ & $G_{\mathrm{TL}}[\mathrm{MPa}]$ \\
\hline 600 & 600 & 12,000 & 0.558 & 0.038 & 0.015 & 40 & 700 & 700 \\
\hline
\end{tabular}

Symbols: $E$ for elastic modulus, $\nu$ for Poisson's ratio and $G$ for shear modulus. Subscripts: 'R' for radial, 'T' for tangential and 'L' for longitudinal to the fibres direction. 


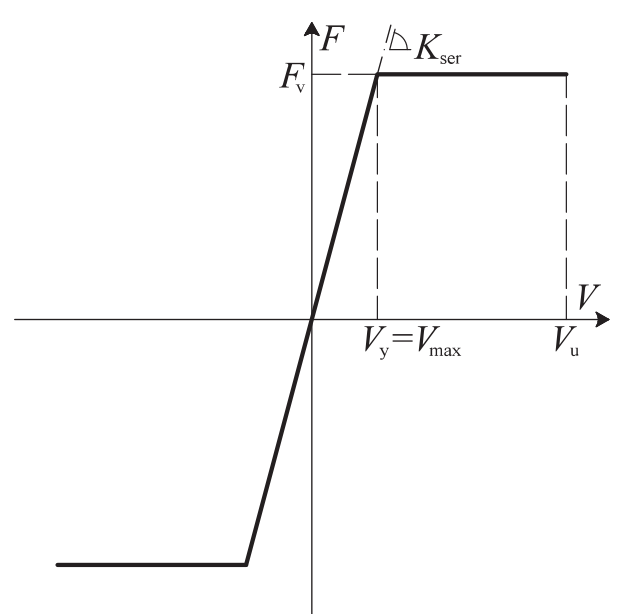

a.

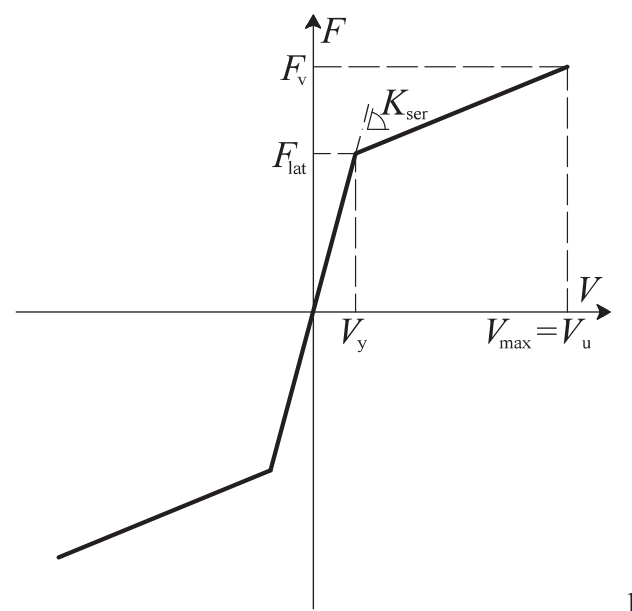

b.

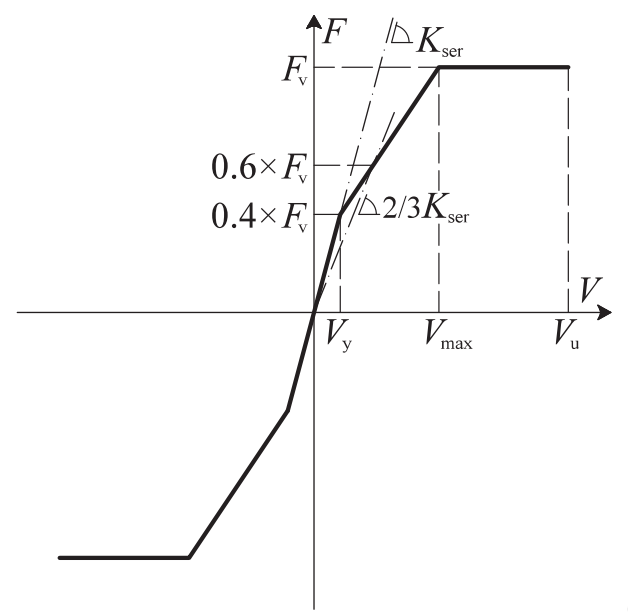

c.

Fig. 4. Load-displacement response of a nailed steel-to-timber joint according to (a) Method I, (b) Method II, and (c) Method III.

performance when shear and tension loads are applied simultaneously is investigated. Analyses are carried out by varying the inclination of the load, with respect to the axis of the connector, between $0^{\circ}$ (i.e. only tension) and $90^{\circ}$ (i.e. only shear). All the simulations are performed using ABAQUS software package [11].

\section{Model description}

The metal connector and the elements where it is anchored are modelled as 3D solid bodies, meshed with cubic elements with reduced integration (C3D8R [11]). The CLT wall and the floor panel are introduced into the analysis to account for the surface-to-surface contact interaction and do not influence the behaviour of the metal connector. Therefore, to limit the computational effort required by the simulations, only the top $10 \mathrm{~mm}$ thickness of those elements are modelled.

The anchoring device has an elasto-plastic isotropic behaviour with Young's modulus equal to $210 \mathrm{GPa}$ and Poisson's ratio set to 0.3 . The proof and ultimate strength of the steel material depend on the connector being analysed and cannot be set $a$ priori. In this study, those strength properties are defined based on the information given in the European Technical Assessments (ETAs) of the devices considered in the simulations. Further details are given in Section 5 .

The CLT wall is modelled as orthotropic elastic, with material parameters taken from Fortino et al. [12] (Picea abies, see Table 1). The floor element can be either a rigid foundation (a steel profile or a concrete basement over which the ground floor is assembled) or another CLT panel (an intermediate floor). In the first situation, an elastic isotropic material is used with Young's modulus equal to $210 \mathrm{GPa}$ and Poisson's ratio set to 0.3 , while in the second situation the same material parameters of the CLT wall are adopted (Table 1).

The nailed steel-to-timber joints are simulated as two-node nonlinear hysteretic springs with three degrees of freedom. Two displacement components simulate the shear response in parallel and in perpendicular to the face lamination of the panel. The third one represents the withdrawal behaviour of the nail under axial actions. Each spring is pinned onto the metal connector (at the nail cap location) and onto the external surface of the timber element (at the nail point location), where the boundary conditions of the model are applied.

The displacement components that simulate the shear response of a nailed joint are coupled by means of the force-based strength domain with quadratic interaction given in Eq. (1).

$\left(\frac{F_{0^{\circ}, i}}{F_{\mathrm{y}}}\right)^{2}+\left(\frac{F_{90^{\circ}, i}}{F_{\mathrm{y}}}\right)^{2} \leqslant 1$

In the expression above, $F_{\mathrm{y}}$ is the yield load of the joint, while $F_{0^{\circ}, i}$ and $F_{90}{ }^{\circ}, i$ are the shear loads in parallel and perpendicular to the face lamination of the panel at the $i$-th analysis step. Further information on this quadratic interaction relationship and how it affects the response of the non-linear springs are given in Rinaldin et al. [10].

\section{Mechanical properties of nailed joints}

Nailed joints in CLT structures are assembled using annular-ringed shank nails (see Fig. 2). Compared to traditional nails with smooth shank, the threaded shank increases the withdrawal capacity, while the conical-shaped cap enhances the clamping to the metal plate and enforces a ductile failure mechanism with two plastic hinges (see Fig. 3c).

In this study, the mechanical properties of the nailed joints are determined according to the calculation models published in literature [13-16]. Furthermore, results are combined with the prescriptions included in the ETAs of nails currently available on the market $[17,18]$.

\subsection{Shear capacity}

The shear capacity of laterally loaded joints with annular-ringed shank nails $\left(F_{\mathrm{v}}\right)$ is the sum of two contributions. According to Eq. (2), the first term denotes the lateral dowel capacity of the nailed joint $\left(F_{\text {lat }}\right)$, while the second term represents the 'rope effect' and is equal to $50 \%$ of the withdrawal capacity of the nail $\left(F_{\mathrm{ax}}\right)$.

$F_{\mathrm{v}}=F_{\text {lat }}+0.5 F_{\mathrm{ax}}$

Nailed joints subjected to shear loads exhibit the so-called 'rope effect' due to the withdrawal of the deformed fasteners from the timber panels [19]; as discussed by Izzi et al. [20], this effect is usually activated once a joint attains its lateral dowel capacity $F_{\text {lat }}$. In such 


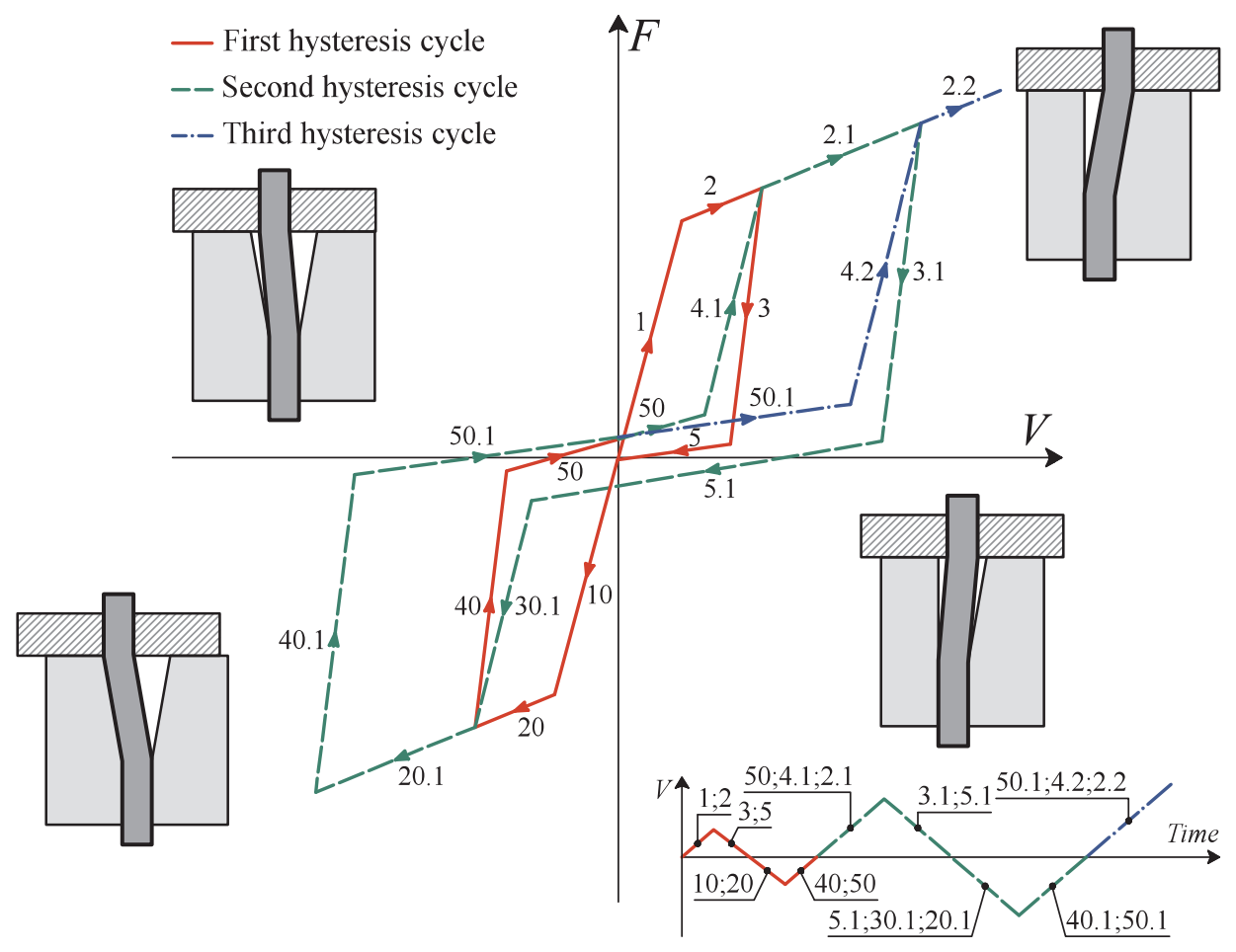

Fig. 5. Hysteretic behaviour of a nailed steel-to-timber joint (adapted from Flatscher [40]).

situation, higher lateral displacements cause the shank to slip over the crushed timber; consequently, the axial displacement of the fastener generates a force in the direction of the shank axis, which increases the shear capacity of the joint.

In Eq. (2), the contribution due to the rope effect is determined according to the design provisions included in the ETAs of Rothoblaas [17] and Simpson Strong-Tie [18] nails. It must be noted that the calculation model prescribed in Eurocode 5 [21] for joints with smooth nails is similar to Eq. (2). However, the standard sets the rope effect to $0.25 F_{\mathrm{ax}}$ and some limiting factors are introduced to avoid relying on the withdrawal of the fastener. In particular, the rope effect for smooth nails is limited to $0.15 F_{\text {lat }}$ while for other nails it is increased up to $0.5 F_{\text {lat }}$.

The lateral dowel capacity of the joint $\left(F_{\text {lat }}\right)$ is defined based on the European Yield Model, originally proposed by Johansen [22]. The analytical model adopted in this study (Eq. (3)) was developed by Hilson [13] considering a nailed steel-to-timber joint with a thick metal plate. According to Eurocode 5 [21] the situation of 'thick plate' is attained when the thickness of the metal plate is greater than or equal to the diameter of the nail. However, as discussed by Izzi et al. [9], the conical-shaped cap enforces a ductile failure mechanism with two plastic hinges also with thinner plates and Eq. (3) is used regardless the thickness of the metal sheet.

$F_{\text {lat }}=\min \left\{\begin{array}{c}f_{\mathrm{h}} t_{1} d \\ f_{\mathrm{h}} t_{1} d\left[\sqrt{2+\frac{4 M_{\mathrm{y}}}{f_{\mathrm{h}} t_{1}^{2} d}}-1\right] \\ 2.0 \sqrt{M_{\mathrm{y}} f_{\mathrm{h}} d}\end{array}\right.$

In the expressions above, $d$ is the diameter of the fastener, $t_{1}$ the pointside penetration depth, while $M_{\mathrm{y}}$ and $f_{\mathrm{h}}$ represent the yield moment of the nail and the embedding strength of timber. The equation giving the lowest lateral dowel capacity identifies the failure mechanism (Fig. 3). Eq. (3a) is associated to a mechanism where there is only embedding of timber and the fastener behaves as a rigid element. Eqs. (3b)-(3c) describe two failure mechanisms in which the yield moment of the fastener is attained (with one and two plastic hinges) together with the embedding of the timber around it.

The yield moment of the nail is defined as the plastic moment capacity of the circular cross-section (Eq. (4)); in the expression below, the symbol $f_{\mathrm{y}}$ denotes the yield strength of the nail, determined according to Eq. (5) [16].

$M_{\mathrm{y}}=\frac{1}{6} f_{\mathrm{y}} d^{3}$

$f_{\mathrm{y}}=1150 d^{-0.3}$

The embedding strength of timber is calculated as shown in Eq. (6), where $\rho$ stands for the average density of timber [15]. Generally, the embedment behaviour of timber depends on the relative orientation between applied load and grain direction [23-26]; however, differences can be disregarded if $d$ is smaller than $8 \mathrm{~mm}[27,28]$.

$f_{\mathrm{h}}=0.10 \rho d^{-0.3}$

Finally, the withdrawal capacity of a nail $F_{\mathrm{ax}}$ is determined according to Eq. (7), where $l_{\text {thr }}$ is the threaded length of the nail shank [14].

$F_{\mathrm{ax}}=0.155 \rho^{0.8} d^{0.6} l_{\mathrm{thr}}$

\subsection{Slip modulus}

The slip modulus of laterally loaded nailed joints is predicted based on the calculation model included in Eurocode 5 [21]; such model was originally developed by Ehlbeck and Larsen [29] for a nailed timber-totimber joint. Based on mechanical relationships (see, e.g., Flatscher [30]), the standard suggests that the slip modulus of a similar steel-totimber joint may be doubled up, leading to Eq. (8). It should be noted that tests carried out by Izzi et al. [9] on single fastener joints proved that Eq. (8) overestimates the experimental slip moduli and suggested that the assumption of rigid plate, which is the basis for doubling the stiffness, might not be valid at low load levels.

$K_{\text {ser }}=2 \frac{\rho^{1.5} d^{0.8}}{30}$ 

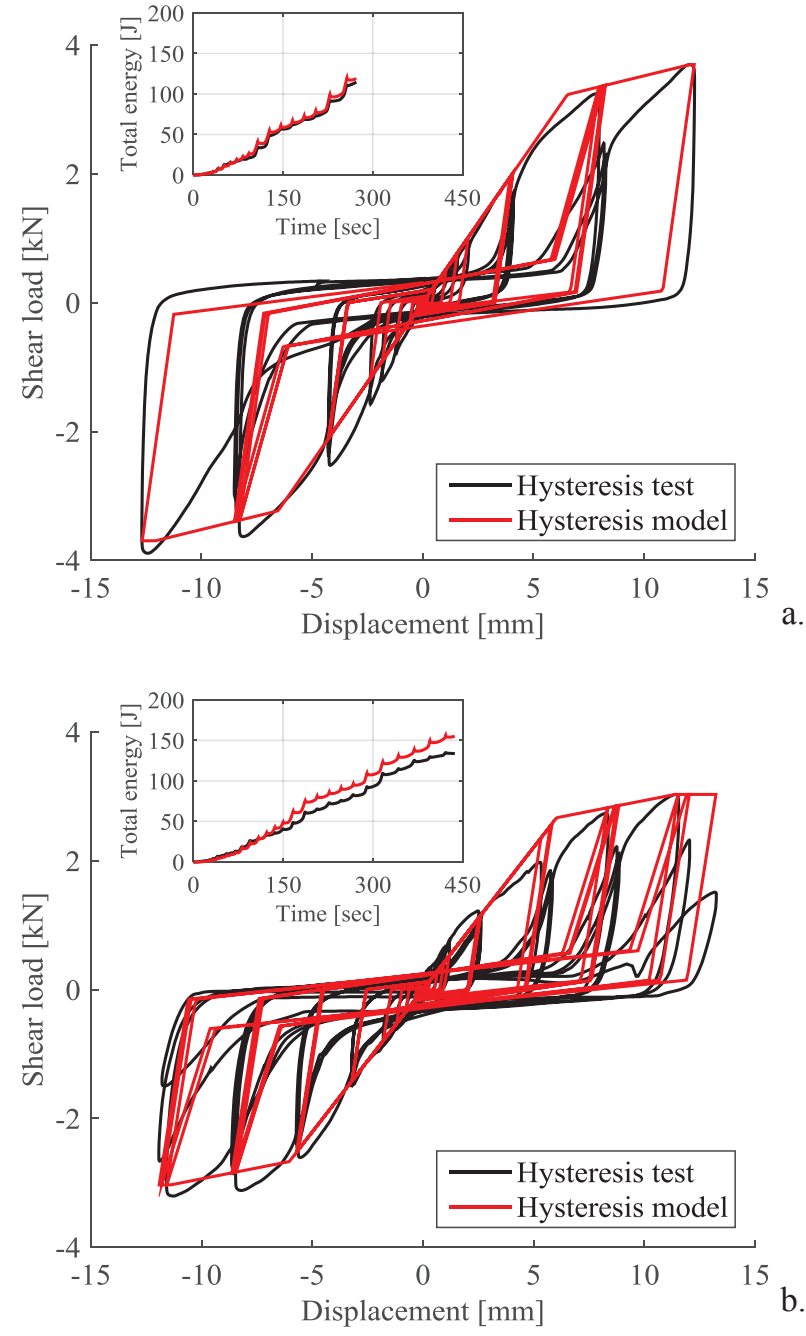

Fig. 6. Comparison between experimental and numerical results of a nailed steel-totimber joint loaded (a) in parallel and (b) in perpendicular to the face lamination of a CLT panel (with close-up on the history of total energy).

Table 2

Experimental setups of the connection systems tested by Casagrande et al. [6].

\begin{tabular}{lllll}
\hline $\begin{array}{l}\text { Metal } \\
\text { connector }\end{array}$ & Wall element & Floor element & $\begin{array}{l}\text { Wall } \\
\text { anchoring }\end{array}$ & $\begin{array}{l}\text { Floor } \\
\text { anchoring }\end{array}$ \\
\hline TTF200 & $\begin{array}{l}\text { CLT panel } \\
\left(\rho=480 \mathrm{~kg} / \mathrm{m}^{3}\right)\end{array}$ & $\begin{array}{l}\text { CLT panel } \\
\left(\rho=480 \mathrm{~kg} / \mathrm{m}^{3}\right)\end{array}$ & $\begin{array}{l}30 \text { nails } \\
(4 \times 60)\end{array}$ & $\begin{array}{l}30 \text { nails } \\
(4 \times 60)\end{array}$ \\
WHT620 & $\begin{array}{l}\text { GLT panel } \\
\left(\rho=420 \mathrm{~kg} / \mathrm{m}^{3}\right)\end{array}$ & $\begin{array}{l}\text { Steel foundation } \\
\text { (rigid) }\end{array}$ & $\begin{array}{l}52 \text { nails } \\
(4 \times 60)\end{array}$ & 1 bolt $(\varnothing 20)$ \\
\hline
\end{tabular}

\section{Load-displacement response of nailed joints}

This section describes the mechanical relationships used to schematize the shear response of a nailed joint. Because tests of single and groups of nailed joints showed slightly different load-displacement responses, such behaviour is schematized according to three methods (Fig. 4). The first one (labelled 'Method I') uses a bilinear relationship with a plastic plateau. The second method (labelled 'Method II') employs a bilinear relationship with a hardening branch. Finally, the third method (labelled 'Method III') adopts a trilinear elasto-plastic relationship.

As discussed in Section 2, the third displacement component of the hysteretic springs models the withdrawal behaviour of the nail. Because the rope effect has been already accounted into the shear components
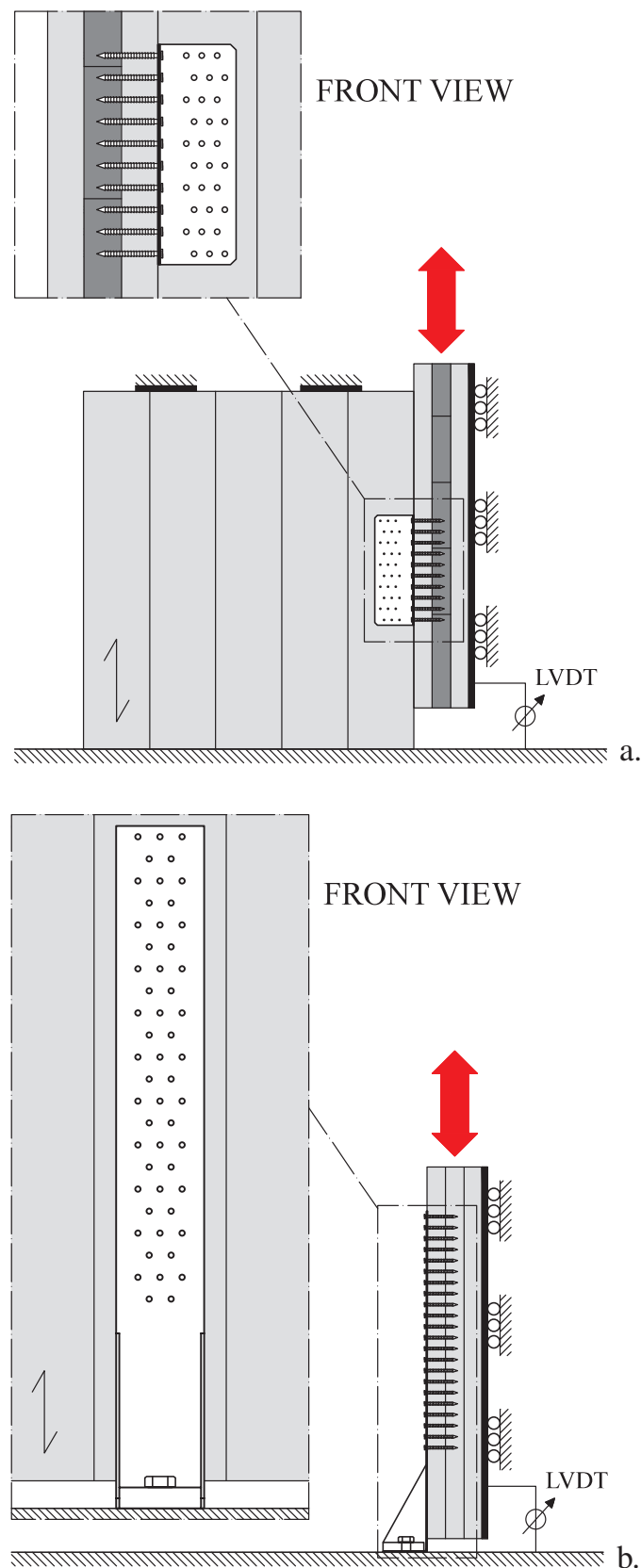

Fig. 7. Schematics of the connection systems reproduced in the simulations: (a) shear test of the TTF200 and (b) tension test of the WHT620.

(see Eq. (2)), this contribution is activated only under pure axial loads. Consequently, for the sake of simplicity, it is taken into account in the simulations as an elastic spring with a brittle failure mechanism after the attainment of the maximum load. The stiffness of the withdrawal component is set to $1250 \mathrm{~N} / \mathrm{mm}$ based on the test results published by Izzi et al. [9], while the maximum load-carrying capacity is determined as shown in Eq. (7).

\subsection{Method I}

The first method schematizes the shear response of a nailed joint with a bilinear elasto-plastic relationship (Fig. 4a). The elastic stiffness is equal to the slip modulus of the joint $K_{\text {ser }}$, while the shear capacity $F_{\mathrm{v}}$ identifies the loads at the transition point between the elastic branch and the plastic plateau, and at the ultimate displacement $V_{\mathrm{u}}$ (where $V_{\mathrm{u}}$ is conventionally set to $20 \mathrm{~mm}$ ). In Fig. $4 \mathrm{a}, V_{\mathrm{y}}$ denotes the yield 
Table 3

Mechanical properties of a nailed steel-to-timber joint, according to Eqs. (2)-(8).

\begin{tabular}{|c|c|c|c|c|c|c|}
\hline Joint type & $M_{\mathrm{y}}[\mathrm{kNmm}]$ & $f_{\mathrm{h}}[\mathrm{MPa}]$ & $F_{\mathrm{ax}}[\mathrm{kN}]$ & $F_{\text {lat }}[\mathrm{kN}]$ & $F_{\mathrm{v}}[\mathrm{kN}]$ & $K_{\mathrm{ser}}[\mathrm{kN} / \mathrm{mm}]$ \\
\hline Nailed joint in CLT (for the TTF200) & 8.09 & 31.67 & 2.19 & 2.03 & 3.12 & 2.13 \\
\hline Nailed joint in GLT (for the WHT620) & 8.09 & 27.71 & 1.97 & 1.89 & 2.88 & 1.74 \\
\hline
\end{tabular}

Table 4

Typical input parameters of a nailed steel-to-timber joint, when the load-displacement response is defined according to Method I.

\begin{tabular}{lll}
\hline & \multicolumn{2}{l}{ Input parameters for Method I } \\
\cline { 2 - 3 } & Connection with TTF200 & Connection with WHT620 \\
\hline$K_{\text {ser }}[\mathrm{kN} / \mathrm{mm}]$ & 2.13 & 1.74 \\
$F_{\mathrm{v}}[\mathrm{kN}]$ & $2.22^{\mathrm{a}}$ & $1.94^{\mathrm{a}}$ \\
Slope \#1 & $K_{\text {ser }}$ & $K_{\text {ser }}$ \\
Slope \#3 & $5 \times K_{\text {ser }}$ & $5 \times K_{\text {ser }}$ \\
Slope \#4 & $2.5 \times K_{\text {ser }}$ & $2.5 \times K_{\text {ser }}$ \\
Separation \#1-\#2 & $F_{\mathrm{v}}$ & $F_{\mathrm{v}}$ \\
Separation \#3-\#5 & $5 \% \times F_{\mathrm{v}}$ & $5 \% \times F_{\mathrm{v}}$ \\
Separation \#50-\#4 & $16 \% \times F_{\mathrm{v}}$ & $16 \% \times F_{\mathrm{v}}$ \\
\hline
\end{tabular}

${ }^{\text {a }}$ Effective strength property, obtained by multiplying the shear capacity $F_{\mathrm{v}}$ given in Table 3 by the effective factor $k_{\text {eff }}$ defined in Equation (12); $k_{\text {eff }}=0.71$ for the TTF200 (30 nails) and $k_{\text {eff }}=0.67$ for the WHT620 (52 nails).
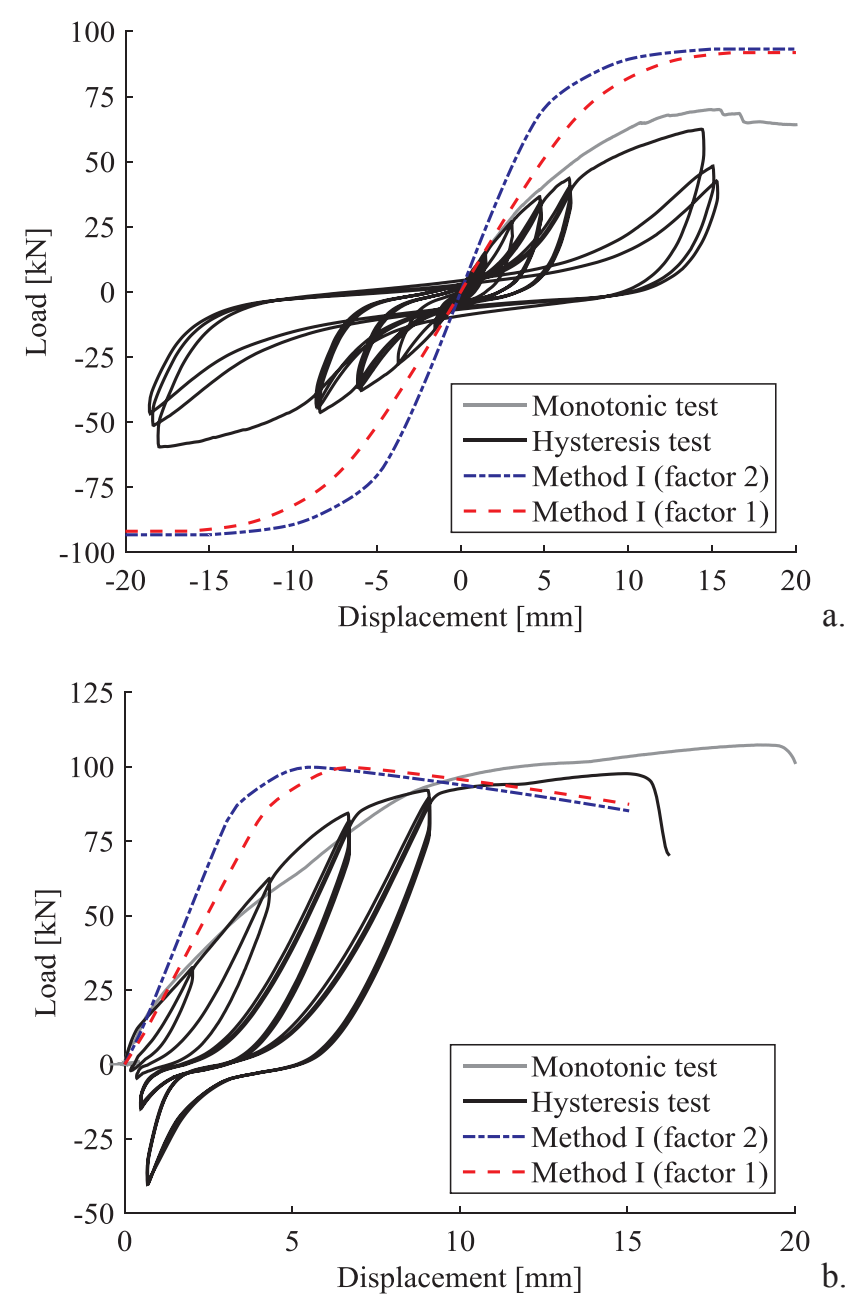

Fig. 8. Comparison between experimental and numerical results of (a) the TTF200 loaded in shear and (b) the WHT620 loaded in tension, when the actual mechanical properties of the nailed joints are used. displacement and $V_{\max }$ the displacement at which $F_{\mathrm{v}}$ is attained, being $V_{\mathrm{y}}=V_{\max }=F_{\mathrm{v}} / K_{\text {ser }}$.

The assumption of elastic behaviour until the attainment of the shear capacity is acceptable since shear tests of single nailed joints showed a linear fashion until $90 \%$ of the shear capacity $F_{\mathrm{v}}$ [9]. However, the displacement at which $F_{\mathrm{v}}$ is attained in the tests is higher compared to the values obtained with this bilinear method, possibly leading to incorrect predictions of $V_{\mathrm{y}}$ (and $V_{\max }$ ) in the analyses.

\subsection{Method II}

The second method schematizes the shear response of a nailed joint based on an elasto-plastic relationship with a hardening branch (Fig. 4b) and is derived taking as a reference the tests of Casagrande et al. [6]. The elastic stiffness is equal to the slip modulus of the joint $K_{\text {ser }}$, while the shear capacity $F_{\mathrm{v}}$ identifies both the maximum load and the load at the ultimate displacement $\left(V_{\max }=V_{\mathrm{u}}\right)$. The yield load is equal to the lateral dowel capacity $F_{\text {lat }}$, as confirmed by an independent numerical study carried out by Izzi et al. [20] on similar test data. Finally, the slope of the hardening branch is determined by assuming that the shear capacity is attained at $V_{\max }=V_{\mathrm{u}}=6 V_{\mathrm{y}}$, being $V_{\mathrm{y}}=F_{\text {lat }} / K_{\text {ser }}$.

\subsection{Method III}

The third method schematizes the shear response of a nailed joint using a trilinear elasto-plastic relationship (Fig. 4c) and is derived based on the tests of Ceccotti et al. [31]. The slope of the elastic branch is equal to the slip modulus $K_{\text {ser }}$, while its maximum load is equal to $40 \%$ of $F_{\mathrm{v}}$. The first inelastic branch has a hardening behaviour and maximum load equal to $F_{\mathrm{v}}$. Its slope is given by the line drawn through the points at $40 \%$ and $60 \%$ of the shear capacity $F_{v}$; the first point lays on the elastic branch, while the second point belongs to the line drawn through the origin of the axis with stiffness equal to $2 / 3 K_{\text {ser }}$. The second inelastic branch has a plastic behaviour until the ultimate displacement $V_{\mathrm{u}}$ (conventionally set to $20 \mathrm{~mm}$ ) and is activated after the attainment of the maximum load, i.e. at $V_{\max }=1.9 F_{\mathrm{v}} / K_{\text {ser }}$

\subsection{Hysteretic behaviour}

Nailed joints subjected to cyclic loads exhibit the pinching effect due to the reduction of stiffness at small displacement amplitudes, when a cavity is formed around the fastener due to timber crushing. Stiffness increases at higher displacement levels, when the nail comes again into contact with the surrounding timber [32].

The hysteretic behaviour of a nailed joint is schematized according to the piecewise-linear law of Fig. 5. The backbone curve (composed of branches $\# 1, \# 2, \# 10$, and $\# 20$ ) is assembled based on the methods discussed in Sections 4.1-4.3. If the joint is unloaded from a positive displacement, branch \#3 is followed; on the contrary, branch \#40 is followed if the unloading starts from a negative displacement. Branches \#5 and \#50 model the gap between the nail shank and the surrounding timber. Finally, branches \#30 and \#4 simulate the mechanical behaviour when the nail comes again into contact with timber.

The unloading (\#3, \#5, and \#30) and reloading (\#40, \#50, and \#4) paths depend on the plastic deformed configuration of the joint. Since typical nailed joints are too slender to attain a failure mechanism with only embedding of timber (see Fig. 3a), this situation is disregarded in the following discussion. In any case, this failure mechanism should be 


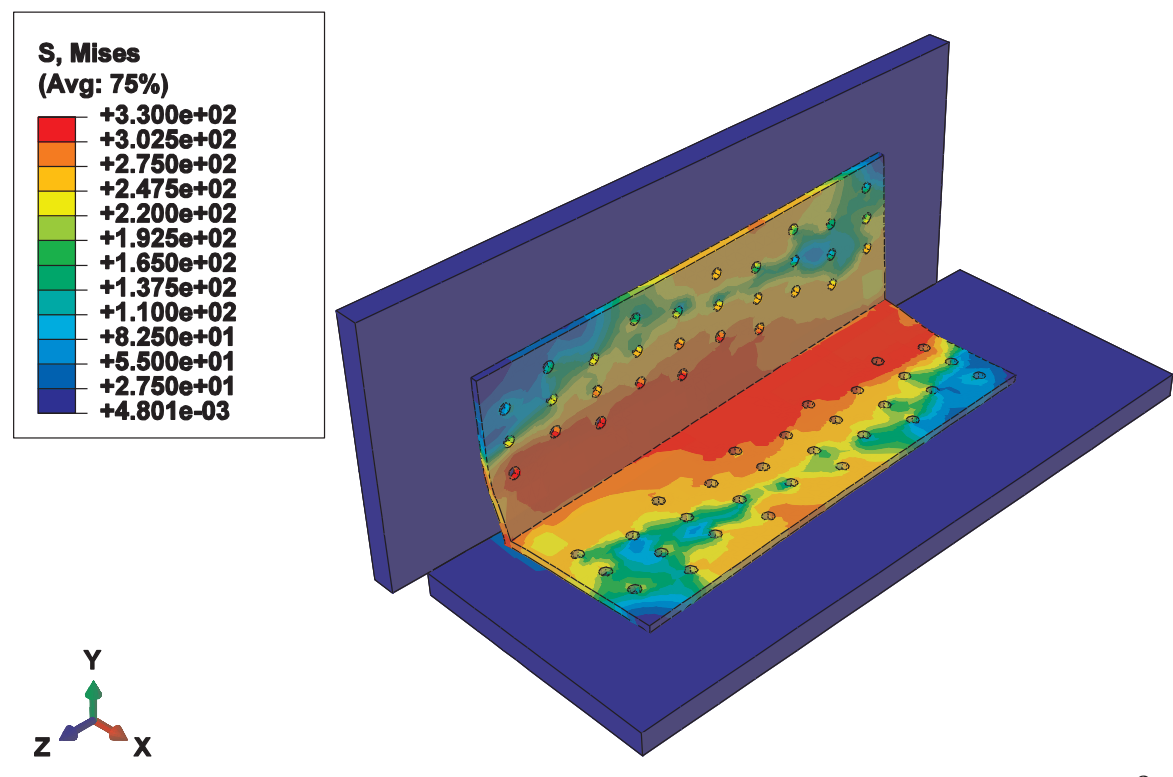

a.

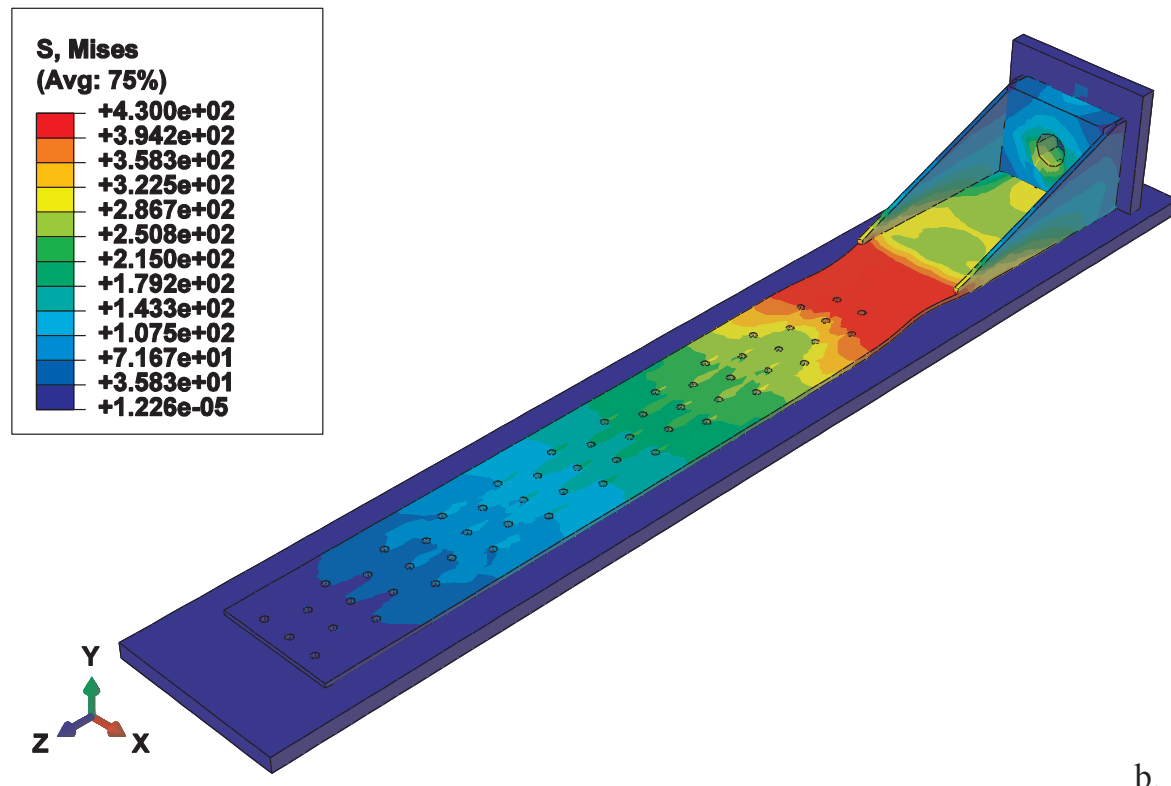

b.

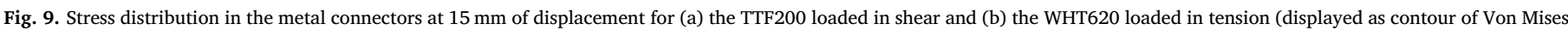
stresses).

carefully avoided in seismic applications due to the slack effect (zero strength and stiffness) and the sudden reduction of the load-carrying capacity caused by timber crushing.

The slopes of branches \#3 and \#4 are defined based on the cyclic tests carried out by Izzi et al. [9] and are set to 5 and 2.5 times $K_{\text {ser }}$, respectively. Similarly, the load at the transition point between branches \#3 and \#5 is assessed from the same test data and is set to $5 \%$ of $F_{i}$, where $F_{i}$ is the load attained on the backbone curve at the $i$-th analysis step. Finally, the load at the transition point between branches \#5 and \#30 is defined using an analytical procedure derived from Hilson [13] and is equal to $F_{\# 5 / \# 30} / F_{\mathrm{v}}$ times $F_{i}$, being $F_{\# 5 / \# 30}$ (Eq. (9)) the load taken by the deformed nail (in bending) at the hysteresis cycle where the shear capacity $F_{\mathrm{v}}$ is attained.

$F_{\# 5 / \# 30}=M_{\mathrm{y}} / b_{1}$

In the equation above, $M_{\mathrm{y}}$ denotes the yield moment of the nail, while $b_{1}$ represents the effective penetration depth of the joint, which depends on its failure mechanism. In this study, $b_{1}$ is determined as in Eq. (10) when failure occurs for embedding of timber and yielding of the nail with one plastic hinge (Fig. 3b), while Eq. (11) is used when two plastic hinges have formed (Fig. 3c).

$b_{1}=t_{1}\left[\sqrt{2+\frac{4 M_{\mathrm{y}}}{f_{\mathrm{h}} t_{1}^{2} d}}-1\right]$

$b_{1}=2 \sqrt{\frac{M_{\mathrm{y}}}{f_{\mathrm{h}} d}}$

The hysteresis model discussed above is validated by comparison with two cyclic shear tests of nailed joints loaded in parallel and perpendicular to the face lamination of a CLT panel. The experimental results taken as a reference are obtained from Izzi et al. [9]. The backbone curves used in the springs are assessed from the tests as prescribed in EN 12512 [33]. Fig. 6 shows the outcomes of this 

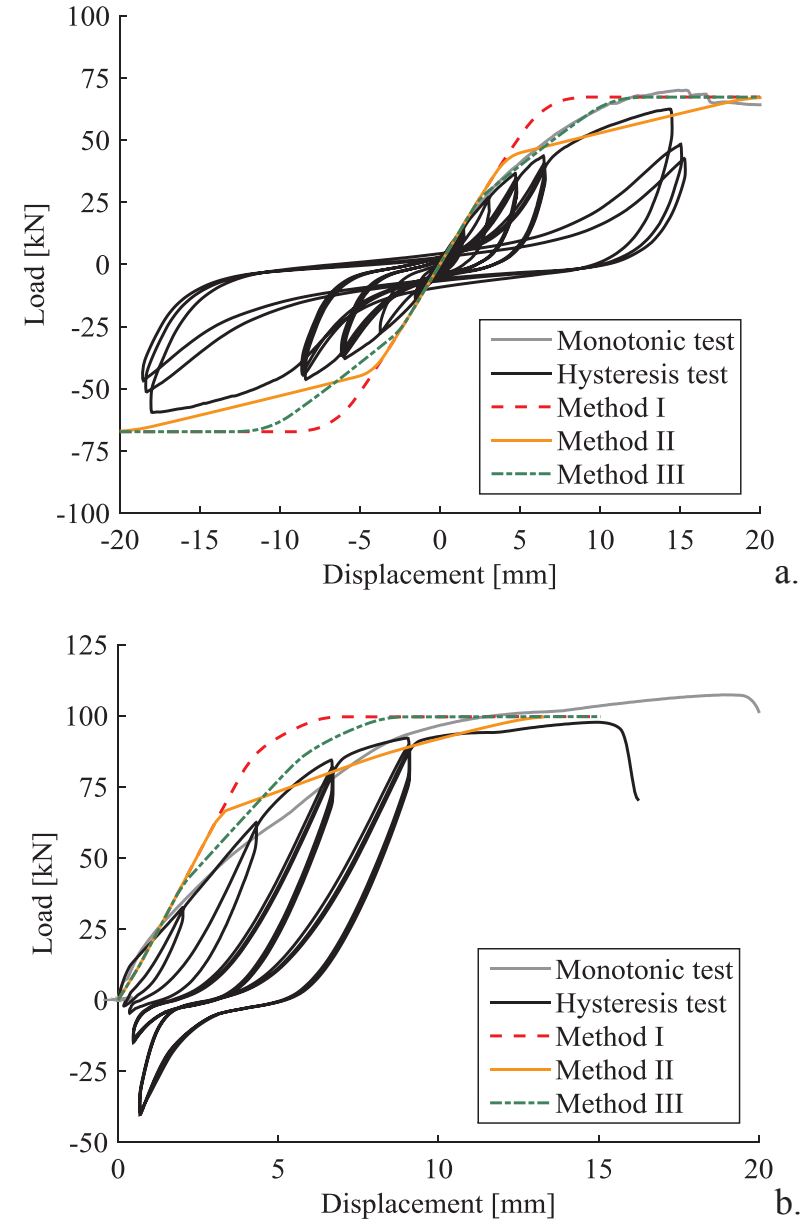

Fig. 10. Comparison between experimental and numerical results of (a) the TTF200 loaded in shear and (b) the WHT620 loaded in tension, when the load-carrying capacity of the nailed joints is reduced to account for the group effect.

comparison. Analyses prove that the hysteresis model is capable of identifying the cyclic response and the energy dissipation, leading to a final difference lower than $10 \%$ between test data and numerical results.

\subsection{Group effect}

The presence of several nails connected to the same metal plate at a very close distance requires consideration of the mutual interaction among the fasteners, i.e. the so-called 'group effect'. Eurocode 5 [21] takes into account this interaction by considering the 'effective number of nails in a row', which depends on their spacing along the grain direction. Furthermore, the standard allows neglecting the group effect when the nails are staggered perpendicular to the grain by at least one diameter.

In this study, the mutual interaction among the nails is considered by introducing the concept of 'effective shear capacity'. In comparison with the approach given in the standard, the number of nails connected to the same metal plate is left unchanged. On the contrary, the shear capacity $F_{\mathrm{v}}$ is reduced by multiplying $F_{\mathrm{lat}}$ and $F_{\mathrm{ax}}$ by the effective factor $k_{\text {ef }}$ defined in Eq. (12).

$k_{\text {eff }}=n^{0.9} / n=n^{-0.1}$

In the equation above, $n$ denotes the total number of nails connected
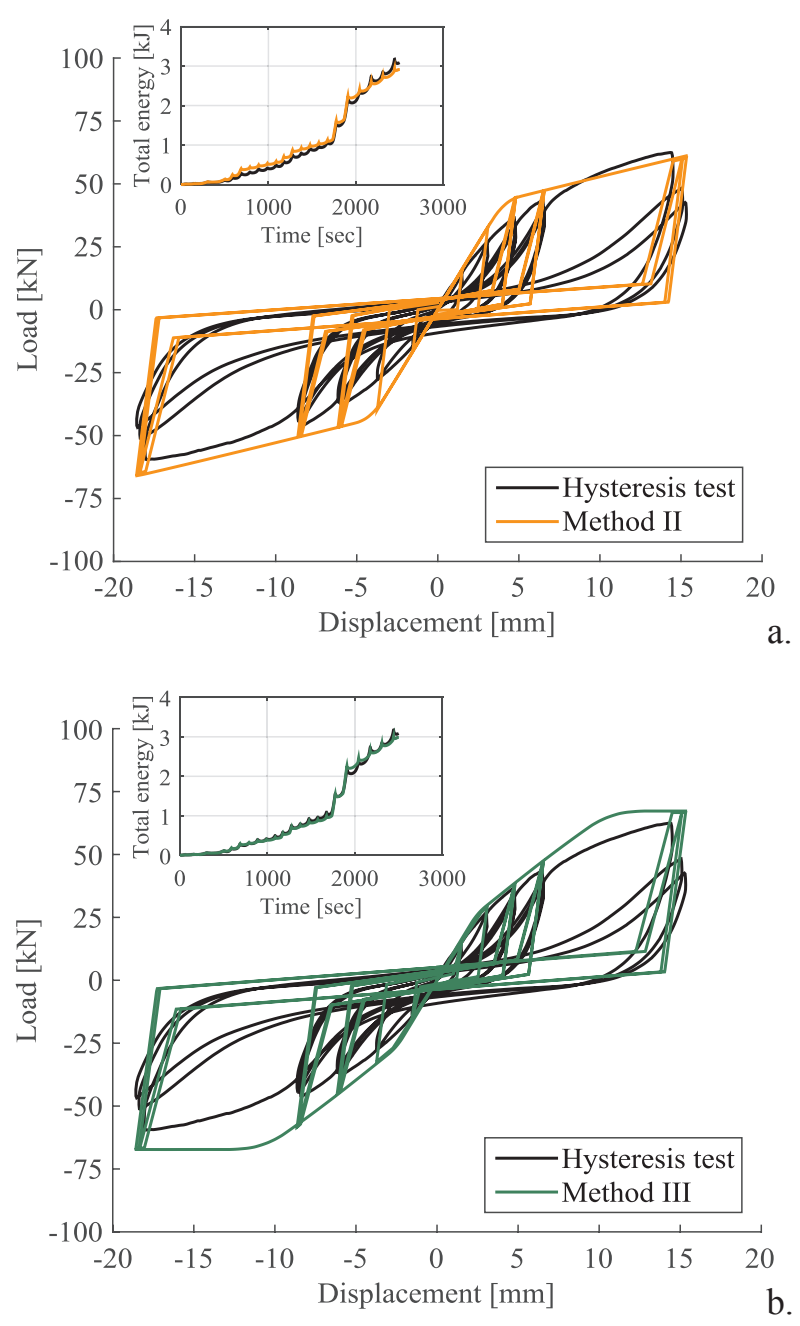

Fig. 11. Comparison between experimental hysteresis and numerical results of the TTF200, when the response of the nailed joints is defined according to (a) Method II and (b) Method III (with close-up on the history of total energy).

to the same metal plate, while $n^{0.9}$ is their effective number, defined as prescribed in Eurocode 5 [21] when the spacing is in the range of $10 d$ to $14 d$ (which corresponds to the usual spacing on the metal connectors). Finally, similarly to what is assumed in the standard, no reduction is applied to the slip modulus of the nailed joints, which is calculated as in Eq. (8).

To achieve the maximum load-carrying capacity in a group of joints, all failure mechanisms of the CLT panels should be avoided. In particular, to prevent any group failure due to splitting or tear-out, the shear capacity of the joints should be predicted considering the wood effective thickness rather than the actual penetration depth of the fasteners $[34,35]$. According to Zarnani and Quenneville [36], such failure mechanisms occur when high loads are transferred to the timber panels (e.g. if groups of metal rivets or screws are used). Therefore, increasing the end-distance from the edge and the spacing between the fasteners might be proper solutions to avoid such issues. However, since the afore-mentioned failure mechanisms have never been observed in steelto-timber joints with threaded nails, they are disregarded in the following discussion. 

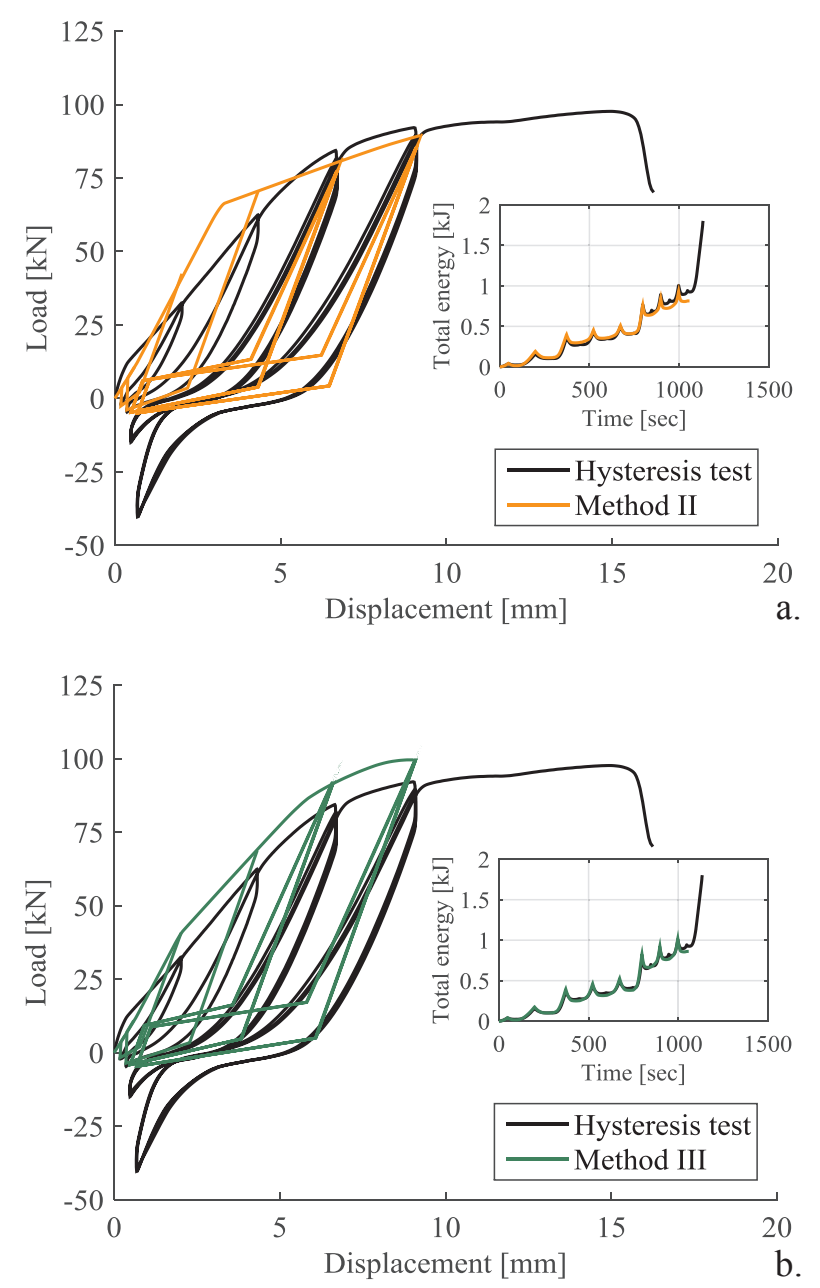

Fig. 12. Comparison between experimental hysteresis and numerical results of the WHT620, when the response of the nailed joints is defined according to (a) Method II and (b) Method III (with close-up on the history of total energy).

\section{Numerical analyses}

Shear and tension tests are reproduced on two wall-to-floor connections tested at the University of Trento (Italy) [6]. The first system is assembled using a TTF200 angle bracket [37], anchored to two CLT panels with 60 nails (30 in each element). The second connection is assembled with a WHT620 hold-down [38], anchored to a Glue-Laminated Timber (GLT) panel with 52 nails and to a steel foundation with a bolt. In this second case, to prevent local buckling and to distribute the load over a larger surface, the anchoring to the foundation is strengthened with a thick washer plate. Both setups employ annularringed shank nails [17] with diameter $d=4.0 \mathrm{~mm}$, penetration depth $t_{1}=54 \mathrm{~mm}$ and threaded length $l_{\text {thr }}=44 \mathrm{~mm}$. Further details of these connections are given in Table 2, while Fig. 7 schematizes the setups used in the tests.

Based on the requirements given in the ETAs of the connectors, the angle bracket is made of S250GD steel with proof strength equal to $250 \mathrm{MPa}$ and ultimate strength equal to $330 \mathrm{MPa}$. The hold-down is made of S355 steel with proof and ultimate strength equal to $355 \mathrm{MPa}$ and $430 \mathrm{MPa}$, respectively. In both cases, the ultimate strength is attained after a $20 \%$ plastic strain. The average density of timber, measured from the actual specimens, is $480 \mathrm{~kg} / \mathrm{m}^{3}$ for CLT and $420 \mathrm{~kg} / \mathrm{m}^{3}$ for GLT. Table 3 summarizes the mechanical properties of the nailed
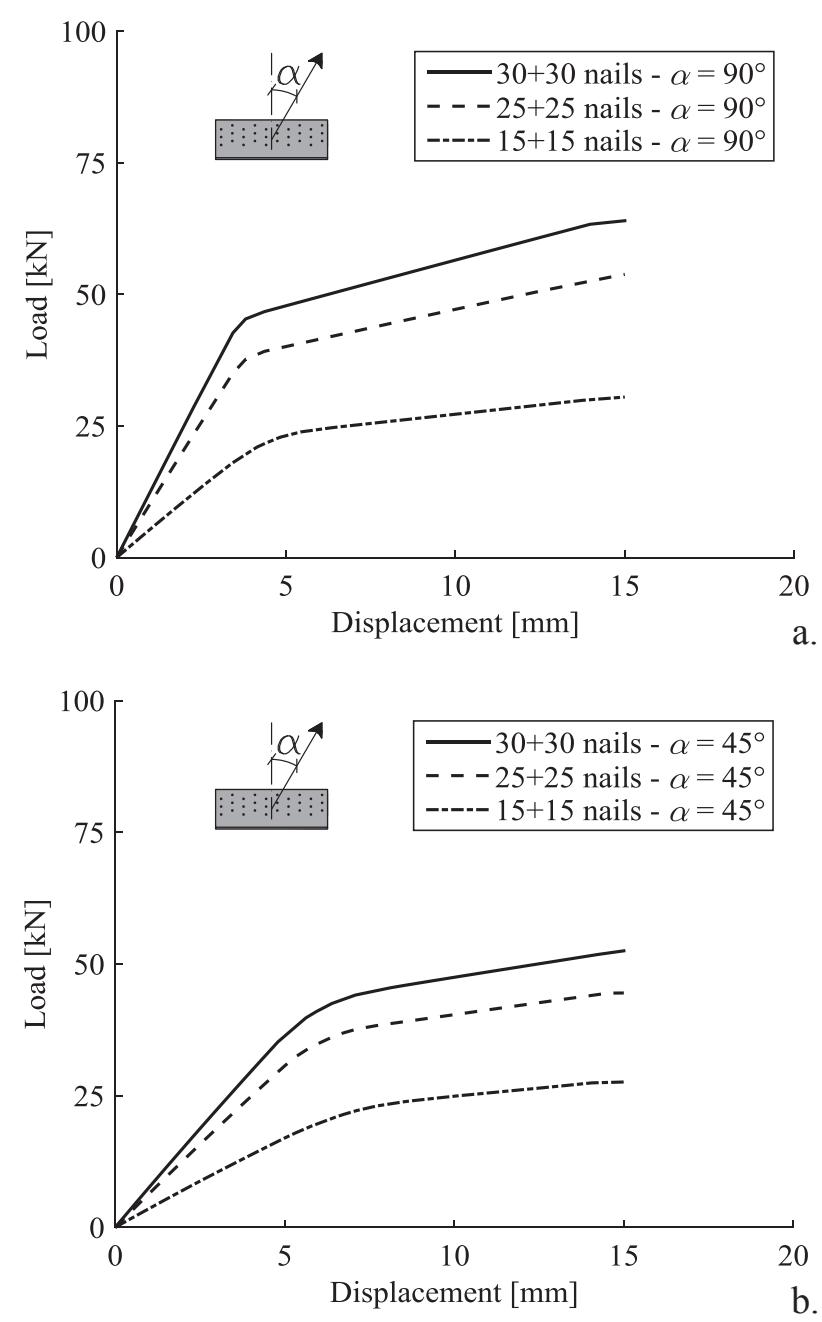

Fig. 13. Load-displacement response of the TTF200 (a) with $\alpha=90^{\circ}$ and (b) with $\alpha=45^{\circ}$, when the number of nails varies from $30+30$ (solid line) to $15+15$ (dashdotted line).

joints, assessed as discussed in Section 3, while Table 4 shows the typical input parameters used in the analyses.

\subsection{Simulations under monotonic loading conditions}

The mechanical behaviour under monotonic conditions is investigated by considering the angle bracket loaded in shear and the hold-down in tension. The analyses are carried out by applying a monotonic displacement to the wall panel (up to $20 \mathrm{~mm}$ and $15 \mathrm{~mm}$, respectively), while the floor element is restrained to its original position.

The first set of simulations does not consider the reduction of strength due to the group effect. The load-displacement response of the nailed joints is defined according to Method I, while the mechanical properties are determined as discussed in Section 3. As pointed out in Section 3.2, shear tests of single nailed steel-to-timber joints highlighted that Eq. (8) overestimates the experimental slip moduli; therefore, analyses are also carried out considering a factor 1 instead of the factor 2 prescribed in Eurocode 5 [21].

Fig. 8 compares experimental results (solid grey line for the monotonic test and solid black line for the hysteresis test) and numerical predictions when $K_{\text {ser }}$ is calculated using a factor 2 (dash-dotted 

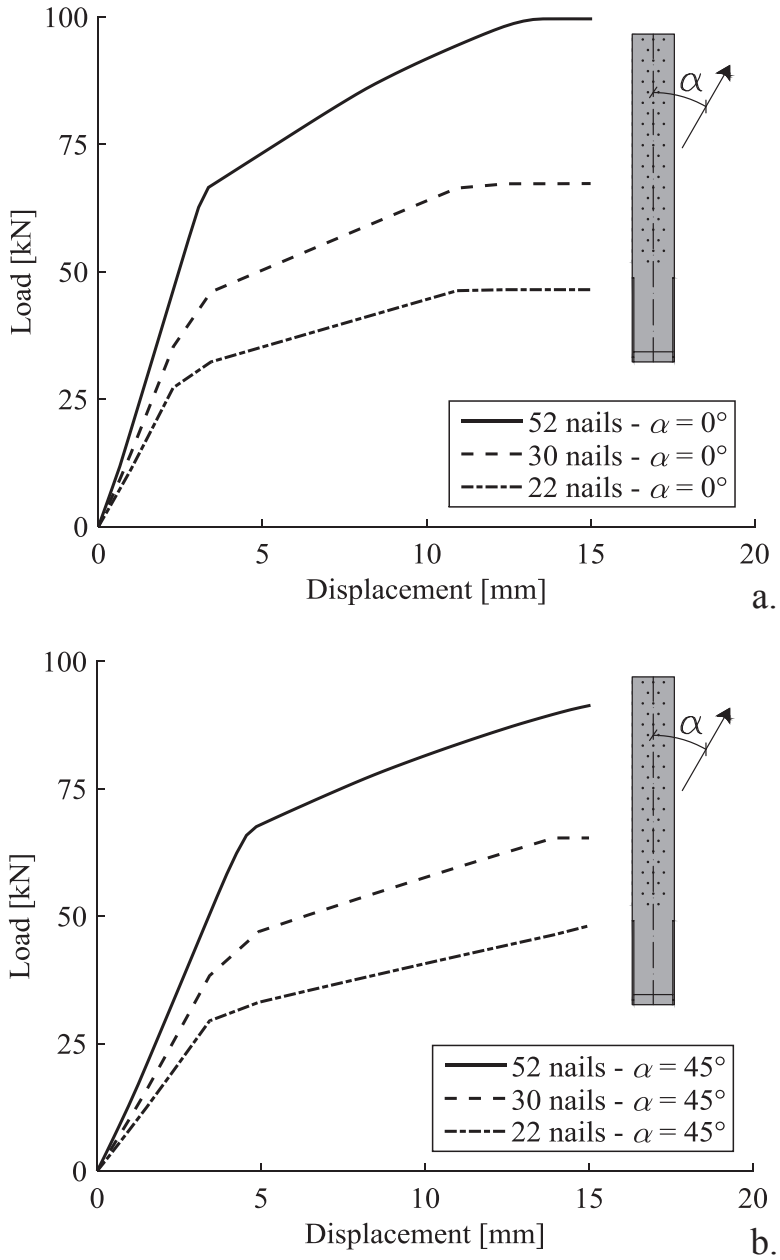

Fig. 14. Load-displacement response of the WHT620 (a) with $\alpha=0^{\circ}$ and (b) with $\alpha=45^{\circ}$, when the number of nails varies from 52 (solid line) to 22 (dash dotted line).

blue line) and a factor 1 (dashed red line). Furthermore, Fig. 9 displays the stress distribution in the metal connectors at $15 \mathrm{~mm}$ of displacement. The angle bracket shows local buckling, while the hold-down exhibits a tensile failure in the metal flange (which justifies the softening behaviour in Fig. 8b). Results of the simulations point out that the factor 1 provides accurate predictions of the elastic stiffness, while the factor 2 leads to unrealistic stiff responses. Furthermore, in both connections, the numerical predictions lead to higher load-carrying capacities compared to the reference test results.

Simulations are subsequently repeated by considering also the other two methods discussed in Section 4 and by including the reduction of strength that accounts for the group effect; all the slip moduli are calculated using a factor 1 instead of the factor 2 given in Eq. (8).

Fig. 10 compares experimental and numerical results when the shear response is defined according to Method I (dashed red line), II (solid orange line) and III (dash-dotted green line). Simulations show that Method II and III provide reliable predictions of the global performance; on the other hand, Method I exhibits similar load-carrying capacities, although it leads to a less accurate identification of the global behaviour.

\subsection{Simulations under cyclic loading conditions}

Cyclic shear and tension tests are reproduced on the previous numerical models, using the same input data of the monotonic analyses. Figs. 11 and 12 compare experimental (black line) and numerical results when the shear response of the nailed joints is defined according to Method II (orange line) and III (green line). Both methods provide reliable predictions of the hysteretic response and the energy dissipation. Method I is not taken into account in this comparison since it provides less accurate results and leads to higher energy dissipations (approximately $10 \%$ higher than in the experimental tests).

The plastic deformations in the metal connectors affect the performance under cyclic loading conditions. As highlighted in Section 5.1, the TTF200 angle bracket shows local buckling close to the bended area; this reduces the global stiffness of the connection (which is lower than the net stiffness resulting from the nailed joints) and increases its ductility. Similarly, the WHT620 hold-down loaded in tension exhibits some plastic deformations in the bottom part of the metal flange, which reduce the stiffness at large displacement amplitudes and influence the shape of the hysteresis cycles.

\subsection{Simulations under bi-axial loading conditions}

The mechanical performance under the simultaneous application of shear and tension loads (bi-axial loading condition) is examined via a parametric numerical study. Simulations are carried out by varying the inclination of the load, with respect to the axis of the connector, between $0^{\circ}$ (only axial load) and $90^{\circ}$ (only shear load). Analyses are subsequently repeated by reducing the number of nails used in the connections. For each connector, three nails patterns are considered: $30+30$ (original pattern), $25+25$, and $15+15$ nails for the angle bracket; 52 (original pattern), 30 and 22 nails for the hold-down. An ultimate displacement equal to $15 \mathrm{~mm}$ [39] is considered in all cases; furthermore, for the sake of simplicity, the load-displacement response of the nailed joints is always defined according to Method II.

Fig. 13 shows the loading curves of the angle bracket when $\alpha=90^{\circ}$ and $\alpha=45^{\circ}$, while Fig. 14 presents similar results for the hold-down when $\alpha=0^{\circ}$ and $\alpha=45^{\circ}$. Finally, Fig. 15 displays the stress distribution in the connectors at the end of the simulations when $\alpha=45^{\circ}$. Results highlight that the loading direction influences both the stiffness and the load-carrying capacity of the connections.

The maximum loads attained in the analyses (at $\alpha=0^{\circ}, 15^{\circ}, 30^{\circ}$, $45^{\circ}, 60^{\circ}, 75^{\circ}$, and $90^{\circ}$ ) are used to create the strength domains shown in Fig. 16 (black lines). Each point is determined as either the maximum of the loading curve or the load at $15 \mathrm{~mm}$ of displacement, whichever occurs first. Numerical results are subsequently compared to the analytical strength domains of the connections, defined as suggested in the ETAs (Eq. (13), red dashed lines).

$\left(\frac{F_{0^{\circ}}}{F_{0^{\circ}, \text { max }}}\right)^{2}+\left(\frac{F_{90^{\circ}}}{F_{90^{\circ}, \text { max }}}\right)^{2} \leqslant 1$

In the equation above, $F_{0^{\circ} \text {,max }}$ and $F_{90^{\circ} \text {,max }}$ represent the maximum strength capacities in the axial and shear direction, while $F_{0^{\circ}}$ and $F_{90^{\circ}}$ denote the actual loads applied to the connection. In Fig. 16, values of $F_{0^{\circ} \text {,max }}$ and $F_{90^{\circ} \text {,max }}$ are set to numerical predictions attained under only axial and shear loads, respectively. Based on the comparisons presented in Fig. 16, numerical results validate the strength domains suggested in the ETAs of the metal connectors, confirming a quadratic interaction relationship between shear and tension loads. 


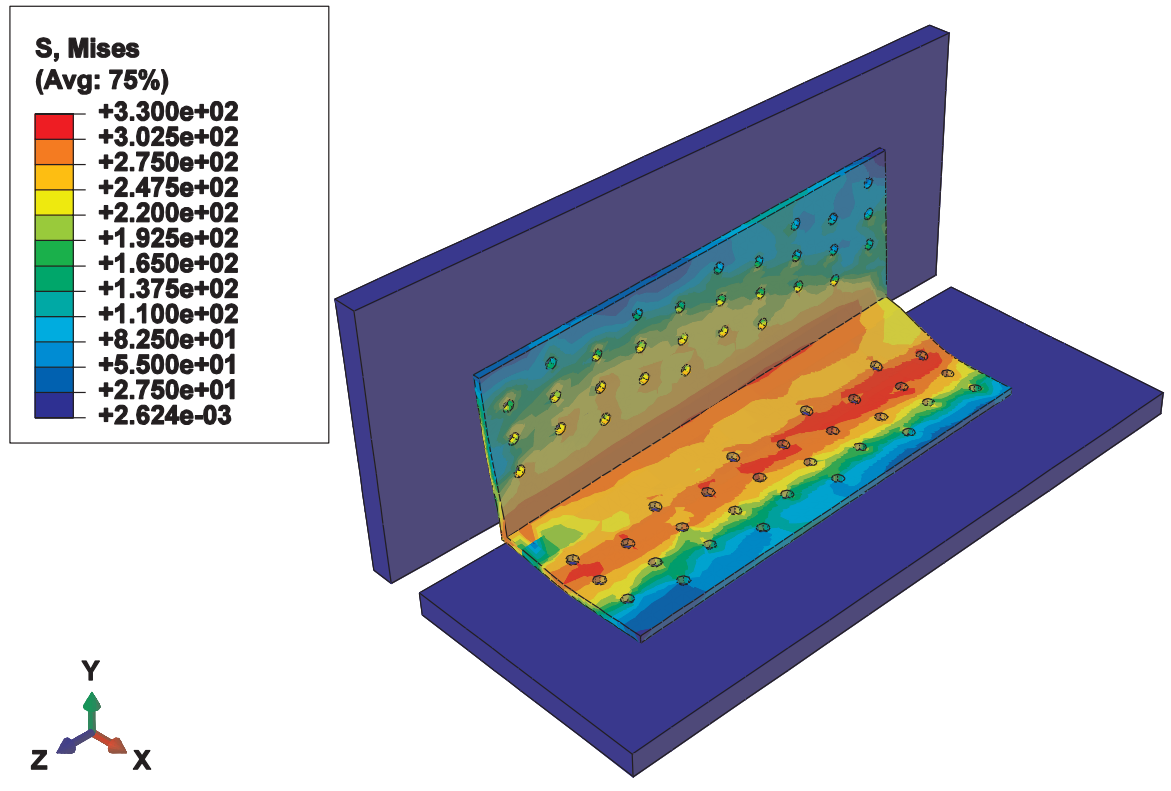

a.
Fig. 15. Stress distribution in the metal connectors at $15 \mathrm{~mm}$ of displacement when $\alpha=45^{\circ}$ (a) for the TTF200 and (b) for the WHT620 (displayed as contour of Von Mises stresses).

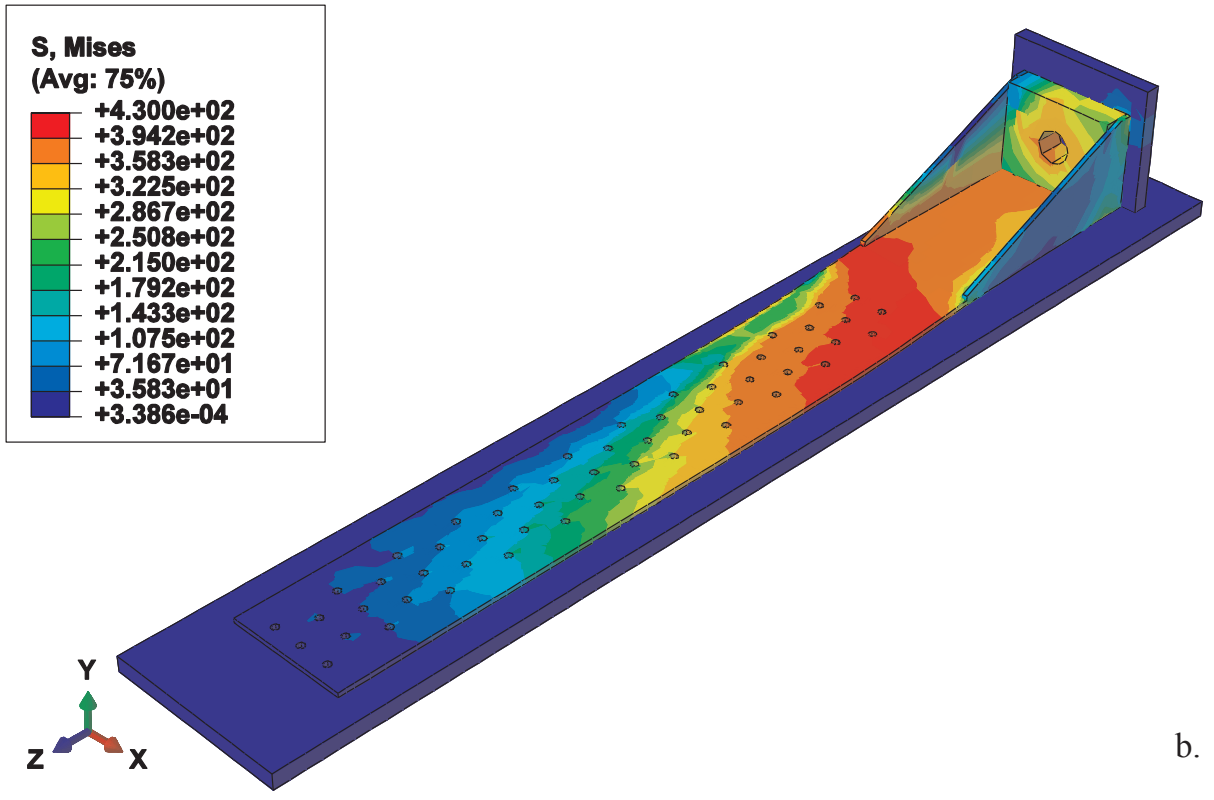

\section{Conclusions}

This paper proposes a numerical model capable of predicting the mechanical behaviour and the failure mechanism of typical wall-tofloor connections used in CLT structures. Great efforts have been devoted to develop a simplified hysteresis that simulates the response of a nailed steel-to-timber joint in CLT. Shear and tension tests are reproduced on connections with angle brackets and hold-downs; numerical results are then compared to the experimental test data of similar configurations, leading to limited differences.

Results of the monotonic analyses highlight that the analytical model prescribed in Eurocode 5 [21] to predict the slip modulus of a nailed steel-to-timber joint overestimates the stiffness at the connection level. Furthermore, simulations proved that it is necessary to consider the group effect in nailed joints (and to reduce their load-carrying capacity) to obtain reliable predictions of the mechanical behaviour of the connections.

Analyses carried out under cyclic conditions exhibit an excellent match with the reference test results, in terms of hysteretic behaviour and energy dissipation. Finally, the performance under bi-axial loading conditions is investigated by varying the inclination of the load and the nails pattern used to fasten the connectors to the wall and floor panels. Simulations showed that the loading direction has a significant influence on the stiffness and load-carrying capacity, and a quadratic interaction relationship is observed between shear and tension loads. 

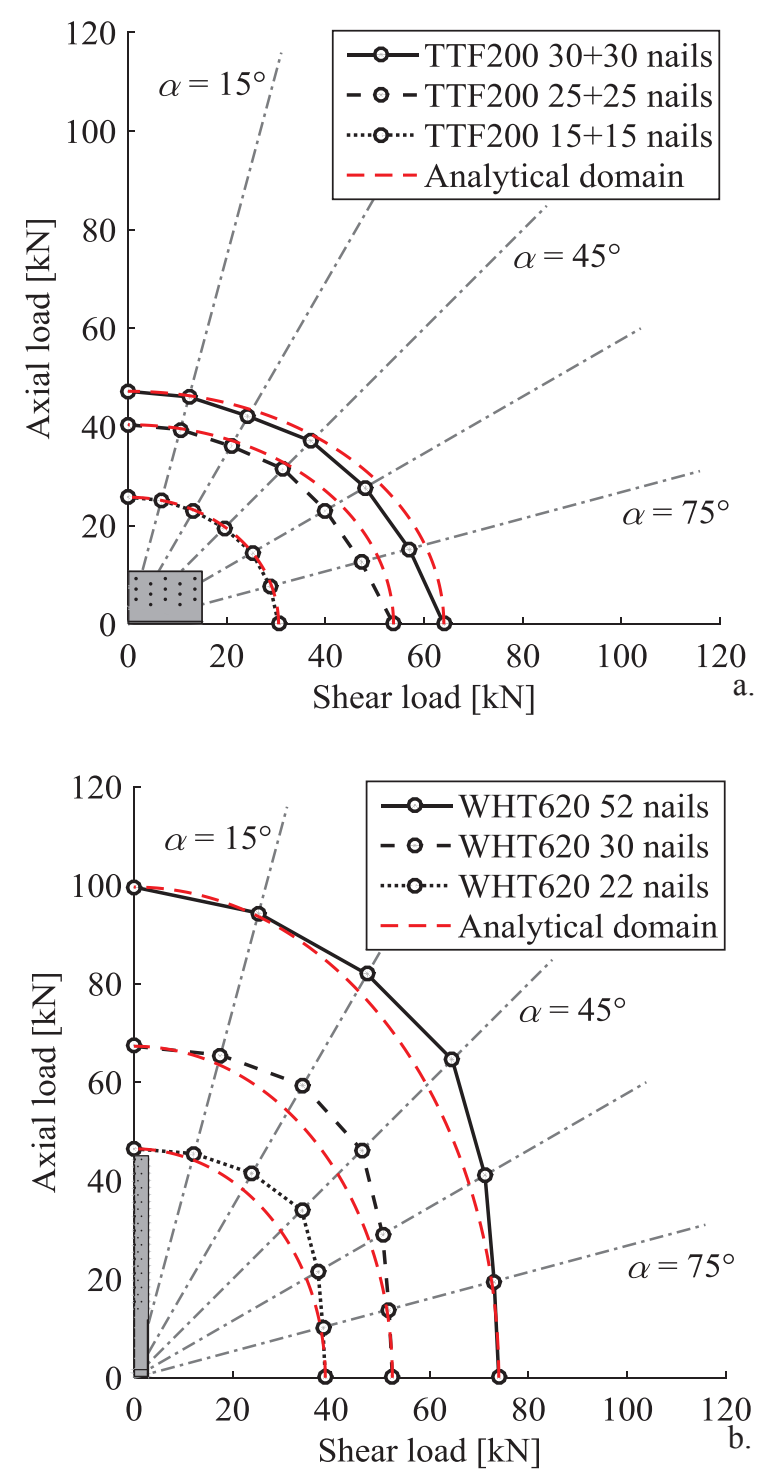

Fig. 16. Comparison between numerical and analytical strength domains, obtained by considering different nails patterns (a) for the TTF200 and (b) for the WHT620.

\section{Acknowledgements}

The experimental test results taken as a reference in this study were obtained as part of the Seismic X-REV research project, funded by Rothoblaas (Italy) and by the Province of Bolzano (Italy). Tests were carried out by the Timber Research Group of the University of Trento (Italy), which is gratefully acknowledged. The authors express their gratitude to Dr. Chiara Bedon (University of Trieste, Italy), for the useful pieces of advice given while performing the simulations. Further acknowledgements are extended to Dr. Giovanni Rinaldin (University of Sassari, Italy), who shared the user element subroutine used in the analyses.

\section{References}

[1] Fragiacomo M, Dujic B, Sustersic I. Elastic and ductile design of multi-storey crosslam massive wooden buildings under seismic actions. Eng Struct 2011;33(11):3043-53. http://dx.doi.org/10.1016/j.engstruct.2011.05.020.

[2] Vogt T, Hummel J, Schick M, Seim W. Experimentelle Untersuchungen für innovative erdbebensichere Konstruktionen im Holzbau. Bautechnik 2013;91(1):1-14. http://dx.doi.org/10.1002/bate.201300083.

[3] Flatscher G, Bratulic K, Schickhofer G. Experimental tests on cross-laminated timber joints and walls. Proceed of the ICE - Struct and Build 2015;168(11):868-77. http://dx.doi.org/10.1680/stbu.13.00085.
[4] Gavric I, Fragiacomo M, Ceccotti A. Cyclic behaviour of typical metal connectors for cross laminated (CLT) structures. Mater Struct 2015;48(6):1841-57. http://dx.doi. org/10.1617/s11527-014-0278-7.

[5] Tomasi R, Smith I. Experimental characterization of monotonic and cyclic loading responses of CLT panel-to-foundation angle bracket connections. J Mater Civil Eng, 2015; 27(6): 04014189, http://dx.doi.org/10.1061/(ASCE)MT.1943-5533. 0001144.

[6] Casagrande D, Polastri A, Sartori T, Loss C, Chiodega M. Experimental campaign for the mechanical characterization of connection systems in the seismic design of timber buildings. In: World Conference on Timber Engineering (WCTE), Vienna, Austria; 2016.

[7] Liu J, Lam F. Experimental test of Cross Laminated Timber connections under bidirectional loading. In: World Conference on Timber Engineering (WCTE), Vienna, Austria; 2016.

[8] Pozza L, Ferracuti B, Massari M, Savoia M. Axial - shear interaction on CLT holddown connections - Experimental investigation. Eng Struct 2018;160:95-110. http://dx.doi.org/10.1016/j.engstruct.2018.01.021.

[9] Izzi M, Flatscher G, Fragiacomo M, Schickhofer G. Experimental investigations and design provisions of steel-to-timber joints with annular-ringed shank nails for CrossLaminated Timber structures. Constr Build Mater 2016;122:446-57. http://dx.doi. org/10.1016/j.conbuildmat.2016.06.072.

[10] Rinaldin G, Amadio C, Fragiacomo M. A component approach for the hysteretic behaviour of connections in cross-laminated wooden structures. Earthquake Eng Struct Dyn 2013;42(13):2023-42. http://dx.doi.org/10.1002/eqe.2310.

[11] ABAQUS 6.12 Documentation. Providence, Rhode Island, USA; 2012.

[12] Fortino S, Mirianon F, Toratti T. A 3D moisture-stress FEM analysis for time dependent problems in timber structures. Mech Time-Depend Mater 2009;13:333-56. http://dx.doi.org/10.1007/s11043-009-9103-z.

[13] Hilson BO (1995) Joints with dowel-type fasteners - Theory. Timber Engineering STEP 1: Basis of design, material properties, structural components and joints, Centrum Hout, Almere, The Netherlands; 1995. P. C3/1-11.

[14] Blaß HJ, Uibel T. Tragfähigkeit von stiftförmigen Verbindungsmitteln in Brettsperrholz. 8, Karlsruher Berichte zum Ingenieurholzbau, Karlsruhe, Germany; 2007. http://dx.doi.org/10.5445/KSP/1000006318.

[15] Sandhaas C, Boukes J, Van de Kuilen J-WG, Ceccotti A. Analysis of X-lam panel-topanel connections under monotonic and cyclic loading. 42nd CIB-W18 Meeting, Dübendorf, Zürich, Swizerland, Paper 42-12-2; 2009.

[16] Sandhaas C, Mergny E. Yield moment of nails. INTER 2016 Meeting, Graz, Austria, Paper Note 1; 2016

[17] ETA-13/0523. European Technical Assessment. ETA, Denmark: Annular ring shank nails and connector screws; 2013.

[18] ETA-04/0013. European Technical Assessment. ETA, Denmark: Nails and screws for use in nailing plates in timber structures; 2015.

[19] Blaß HJ, Sandhaas C. Timber engineering - principles for design. Karlsruhe, Germany: KIT Scientific Publishing; 2017. http://dx.doi.org/10.5445/KSP/ 1000069616.

[20] Izzi M, Rinaldin G, Polastri A, Fragiacomo M. A hysteresis model for timber joints with dowel-type fasteners. Eng Struct 2018;157:170-8. http://dx.doi.org/10.1016/ j.engstruct.2017.12.011.

[21] EN 1995-1-1:2004/A2. Eurocode 5: Design of timber structures. Part 1-1: General. Common rules and rules for buildings. CEN, Belgium; 2014.

[22] Johansen KW. Theory of timber connections. Int Assoc Bridge and Struct Eng 1949;9:249-62. http://dx.doi.org/10.5169/seals-9703.

[23] Blaß HJ, Schädle P. Ductility aspects of reinforced and non-reinforced timber joints. Eng Struct 2011;33(11):3018-26. http://dx.doi.org/10.1016/j.engstruct.2011.02. 001.

[24] Glišović I, Boško S, Tatjana K-M. Embedment test of wood for dowel-type fasteners. Wood Res 2012;57(4):639-50.

[25] Pedersen MU. Dowel type timber connections - Strength modelling [Ph.D. Thesis]. Technical University of Denmark, Copenhagen, Denmark; 2002.

[26] Sewata K, Yasumura M. Determination of embedding strength of wood for doweltype fasteners. J Wood Sci 2002;48(2):138-46. http://dx.doi.org/10.1007/ BF00767291.

[27] Hong J-P, Barrett D. Three-dimensional finite-element modeling of nailed connections in wood. J Struct Eng 2010;136(6):715-22. http://dx.doi.org/10.1061/ASCE ST.1943-541X.0000160.

[28] Zhou T, Guan Z. Review of existing and newly developed approaches to obtain timber embedding strength. Prog Struct Mat Eng 2006;8(2):49-67. http://dx.doi. org/10.1002/pse.213.

[29] Ehlbeck J, Larsen HJ. Eurocode 5 - design of timber structures: joints. Madison, Wisconsin, USA: International Workshop on Wood Connectors; 1993.

[30] Flatscher G. Evaluation and approximation of timber connection properties for displacement-based analysis of CLT wall systems. Graz, Austria: Graz University of Technology; 2017. http://dx.doi.org/10.3217/978-3-85125-557-7.

[31] Ceccotti A, Fragiacomo M, Giordano S. Long-term and collapse tests on a timberconcrete composite beam with glued-in connection. Mater Struct 2007;40(1):15-25. http://dx.doi.org/10.1617/s11527-006-9094-z.

[32] Foliente GC. Hysteresis modeling of wood joints and structural systems. J Struct Eng 1995;121(6):1013-22. http://dx.doi.org/10.1061/(ASCE)0733-9445(1995) 121:6(1013)

[33] EN 12512:2001/A1. Timber structures. Test methods. Cyclic testing of joints made with mechanical fasteners. CEN, Belgium; 2005.

[34] Zarnani P, Quenneville P. Splitting strength of small dowel-type timber connections: rivet joint loaded perpendicular to grain. J Struct Eng 2014;140(10):04014064. http://dx.doi.org/10.1061/(ASCE)ST.1943-541X. 0001039. 
[35] Zarnani P, Quenneville P. Group tear-out in small-dowel-type timber connections: brittle and mixed failure modes of multinail joints. J Struct Eng 2015;141(2):04014110. http://dx.doi.org/10.1061/(ASCE)ST.1943-541X. 0001053.

[36] Zarnani P, Quenneville P. New design approach for controlling brittle failure modes of small-dowel-type connections in Cross-laminated Timber (CLT). Constr Build Mater 2015;100:172-82. http://dx.doi.org/10.1016/j.conbuildmat.2015.09.049.

[37] ETA-11/0496. European Technical Assessment. Three-dimensional nailing plate (Angle bracket for timber-to-timber or timber-to-concrete or steel connections). ETA, Denmark; 2014.
[38] ETA-11/0086. European Technical Assessment. Three-dimensional nailing plate (Angle brackets and hold-downs for timber-to-timber or timber-to-concrete or steel connections). ETA, Denmark; 2015.

[39] EN 26891. Timber structures. Joints made with mechanical fasteners. General principles for the determination of strength and deformation characteristics. CEN, Belgium; 1991.

[40] Flatscher G. Außergewöhnliche Einwirkung ,Erdbeben - Überlegungen zur versuchstechnischen Erfassung der Verbindungstechnik im Holz-Massivbau [MS Thesis]. Graz University of Technology, Graz, Austria; 2010. 